\title{
PENYELESAIAN MASALAH NILAI BATAS UNTUK PERSAMAAN DIFERENSIAL FRAKSIONAL LINIER ORDE $2 \alpha$ DENGAN TURUNAN TIPE CAPUTO
}

\author{
RATNA HAYANI TSANI*, MAHDHIVAN SYAFWAN \\ Program Studi S1 Matematika, \\ Fakultas Matematika dan Ilmu Pengetahuan Alam, Universitas Andalas, \\ Kampus UNAND Limau Manis Padang, Indonesia. \\ email : ratnahasyani@gmail.com,mahdhivan@sci.unand.ac.id
}

Diterima 15 Desember 2020 Direvisi 29 Desember 2020 Dipublikasikan 12 Januari 2021

\begin{abstract}
Abstrak. Dalam penelitian ini diselesaikan masalah nilai batas untuk persamaan diferensial fraksional linier orde $2 \alpha$ dengan turunan tipe Caputo. Teorema-teorema utama menyajikan bentuk umum dan bentuk khusus solusi dari persamaan diferensial serta beberapa contoh yang mengilustrasikan teorema utama yang dipaparkan.
\end{abstract}

Kata Kunci: Masalah nilai batas, persamaan diferensial fraksional linier orde $2 \alpha$,turunan tipe Caputo

\section{Pendahuluan}

Persamaan diferensial fraksional adalah suatu persamaan yang memuat satu atau beberapa fungsi tak diketahui beserta turunan-turunan fraksional terhadap satu atau beberapa variabel bebas. Persamaan diferensial fraksional pertama kali diperkenalkan oleh L'Hôpital pada tahun 1695. Bentuk umum persamaan dari diferensial fraksional linier orde $n \alpha$ dengan $\alpha \in(m-1, m), m, n \in \mathbb{N}$, diberikan oleh persamaan berikut [7]:

$$
D^{n \alpha} x(t)+a_{1} D^{(n-1) \alpha} x(t)+a_{2} D^{(n-2) \alpha} x(t)+\cdots+a_{n} x(t)=f(t),
$$

dimana $D^{n \alpha}$ menyatakan turunan fraksional orde $n \alpha$ dan $a_{j}, j=1,2,3, \cdots, n$ adalah konstanta.

Beberapa peneliti sebelumnya telah menggunakan operator turunan Caputo dalam penelitiannya, salah satunya oleh 'Aisy dan Husna dalam literatur [1], yaitu solusi sistem persamaan diferensial fraksional linier orde fraksional dengan turunan tipe Caputo serta oleh Sari dan Baqi dalam literatur [5], yaitu penggunaan metode Mittag-Leffler untuk menyelesaikan persamaan diferensial fraksional linier dengan koefisien konstan, dimana juga menggunakan operator turunan tipe Caputo. Dalam

*penulis korespondensi 
artikel ini kembali akan digunakan turunan tipe Caputo dalam menyelesaikan persamaan diferensial fraksional linier orde $2 \alpha$ berikut.

$$
D^{2 \alpha} x(t)+a_{0} D^{\alpha} x(t)+b_{0} x(t)=0, \quad t \in\left[t_{0}, t_{1}\right], t_{0}>0,
$$

dengan syarat batas

$$
x\left(t_{0}\right)=x_{0}, \quad x\left(t_{1}\right)=x_{1},
$$

yang dalam hal ini $a_{0}, b_{0}$ merupakan konstanta dan $D^{\alpha}$ adalah turunan fraksional tipe Caputo orde $\alpha$. Persamaan (1.2) bersama syarat batas (1.3) disebut sebagai masalah nilai batas untuk persamaan diferensial fraksional orde $2 \alpha$. Pada artikel ini akan dibahas formulasi eksplisit solusi persamaan (1.2) dengan syarat batas (1.3) yang merujuk pada literatur [9] yang mana membahas tentang solusi sistem persamaan diferensial. Adapun tujuan penulisan artikel ini adalah untuk mengetahui secara eksplisit solusi dari persamaan (1.2) dengan syarat batas (1.3) dimana nilai $\alpha$ berada pada selang $m-1<\alpha<m, \quad \alpha \in \mathbb{R}, \quad m \in \mathbb{N}$.

\section{Landasan Teori}

Dalam bab ini akan dijabarkan beberapa teori terkait dengan permasalahan yang akan dibahas pada bab selanjutnya, yaitu fungsi Gamma, fungsi Beta, fungsi Mittag-Leffler, dan turunan fraksional tipe Caputo.

Definisi 2.1. [11] Fungsi Gamma dinyatakan sebagai $\Gamma(n)$, didefinisikan sebagai berikut:

$$
\Gamma(n)=\int_{0}^{\infty} x^{n-1} e^{-x} d x, \quad n>0 .
$$

Definisi 2.2. [8] Fungsi Beta didefinisikan sebagai berikut:

$$
B(p, q)=\int_{0}^{1} x^{p-1}(1-x)^{q-1} d x, x \in \mathbb{R}, p, q \in \mathbb{C},
$$

dimana $p>0$ dan $q>0$.

Definisi 2.3. [8] Fungsi Mittag-Leffler satu parameter didefinisikan sebagai berikut:

$$
E_{\alpha}(z)=\sum_{k=0}^{\infty} \frac{z^{k}}{\Gamma(\alpha k+1)}, \alpha>0, z \in \mathbb{C} .
$$

Fungsi Mittag-Leffler dua parameter didefinisikan sebagai berikut:

$$
E_{\alpha, \beta}(z)=\sum_{k=0}^{\infty} \frac{z^{k}}{\Gamma(\alpha k+\beta)}, \quad \alpha, \beta>0, \quad z \in \mathbb{C} .
$$

Berikut ini diberikan definisi turunan fraksional tipe Caputo. 
Definisi 2.4. [10] Turunan fraksional Caputo orde $\alpha \in \mathbb{R}$ dari fungsi $f(t)$ dengan $m-1<\alpha<m, m \in \mathbb{N}$, dinotasikan dengan $D^{\alpha} f(t)$, didefinisikan sebagai berikut:

$$
D^{\alpha} f(t)=\frac{1}{\Gamma(m-\alpha)} \int_{0}^{t} \frac{f^{(m)}(\tau) d \tau}{(t-\tau)^{\alpha+1-m}}, m-1<\alpha<m, m \in \mathbb{N}
$$

dimana $f^{(m)}(\tau)$ adalah turunan ke-m dari fungsi $f(\tau)$ dan $\Gamma(m-\alpha)$ menyatakan fungsi gamma dari $(m-\alpha)$.

Teorema 2.5. [4] Turunan fraksional Caputo untuk fungsi $f(t)=t^{p}$ adalah

$$
D^{\alpha} t^{p}= \begin{cases}\frac{\Gamma(p+1)}{\Gamma(p-\alpha+1)} t^{p-\alpha}, & m-1<\alpha<m, \quad p>m-1 \\ 0, & m-1<\alpha<m, \quad p \leq m-1, \quad p \in \mathbb{N} .\end{cases}
$$

Berikut turunan fraksional Caputo ke- $\alpha$ dan ke- $2 \alpha$ dari fungsi Mittag-Leffler $E_{\alpha}\left(\lambda t^{\alpha}\right)[2]$. Dengan menggunakan Definisi 2.3, diperoleh

$$
\begin{aligned}
D^{\alpha} E_{\alpha}\left(\lambda t^{\alpha}\right) & =\lambda E_{\alpha}\left(\lambda t^{\alpha}\right), \\
D^{2 \alpha} E_{\alpha}\left(\lambda t^{\alpha}\right) & =\lambda^{2} E_{\alpha}\left(\lambda t^{\alpha}\right) .
\end{aligned}
$$

\section{Formulasi Solusi}

Perhatikan kembali persamaan (1.2). Suatu fungsi $x(t)$ dikatakan solusi bagi persamaan (1.2) jika $x(t)$ memenuhi persamaan (1.2) tersebut. Untuk mendapatkan solusi persamaan (1.2) tersebut, misalkan

$$
x(t)=E_{\alpha}\left(\lambda t^{\alpha}\right),
$$

yang dalam hal ini $E_{\alpha}\left(\lambda t^{\alpha}\right)$ adalah fungsi Mittag-Leffler satu parameter dengan parameter $\lambda$. Subtitusikan, persamaan (3.1) ke persamaan (1.2), diperoleh:

$$
\begin{aligned}
D^{2 \alpha}\left(E_{\alpha}\left(\lambda t^{\alpha}\right)\right)+a_{0} D^{\alpha}\left(E_{\alpha}\left(\lambda t^{\alpha}\right)\right)+b_{0} E_{\alpha}\left(\lambda t^{\alpha}\right) & =0, \\
\lambda^{2} E_{\alpha}\left(\lambda t^{\alpha}\right)+a_{0} \lambda E_{\alpha}\left(\lambda t^{\alpha}\right)+b_{0} E_{\alpha}\left(\lambda t^{\alpha}\right) & =0, \\
\left(\lambda^{2}+a_{0} \lambda+b_{0}\right) E_{\alpha}\left(\lambda t^{\alpha}\right) & =0 .
\end{aligned}
$$

Dari persamaan (3.2) diperoleh bahwa fungsi Mittag-Leffler (3.1) merupakan solusi dari persamaan (1.2), jika $\lambda$ memenuhi persamaan kuadrat berikut.

$$
\lambda^{2}+a_{0} \lambda+b_{0}=0
$$

Persamaan (3.3) disebut sebagai persamaan karakteristik dari persamaan (1.2).

Terdapat tiga kemungkinan akar karakteristik bagi persamaan karakteristik (3.3), yaitu

(1) $\lambda_{1}, \lambda_{2} \in \mathbb{R}$ dengan $\lambda_{1} \neq \lambda_{2}$.

(2) $\lambda_{1}, \lambda_{2} \in \mathbb{R}$ dengan $\lambda_{1}=\lambda_{2}$.

(3) $\lambda_{1}=p+i q, \lambda_{2}=p-i q$, dengan $p, q \in \mathbb{R}$ dan $i=\sqrt{-1}$.

Untuk Kasus 1, solusi persamaan (1.2) dengan syarat batas (1.3) diberikan dalam teorema berikut. 
Teorema 3.1. Untuk persamaan diferensial fraksional (1.2), jika $\lambda_{1}, \lambda_{2} \in \mathbb{R}$ dengan $\lambda_{1} \neq \lambda_{2}$ adalah akar-akar persamaan karakteristik (3.3), maka solusi dari persamaan (1.2) adalah

$$
x(t)=C_{1} E_{\alpha}\left(\lambda_{1} t^{\alpha}\right)+C_{2} E_{\alpha}\left(\lambda_{2} t^{\alpha}\right),
$$

dengan $C_{1}$ dan $C_{2}$ memenuhi sistem persamaan linier berikut.

$$
\left(\begin{array}{cc}
E_{\alpha}\left(\lambda_{1} t_{0}^{\alpha}\right) & E_{\alpha}\left(\lambda_{2} t_{0}^{\alpha}\right) \\
E_{\alpha}\left(\lambda_{1} t_{1}^{\alpha}\right) & E_{\alpha}\left(\lambda_{2} t_{1}^{\alpha}\right)
\end{array}\right)\left(\begin{array}{l}
C_{1} \\
C_{2}
\end{array}\right)=\left(\begin{array}{l}
x_{0} \\
x_{1}
\end{array}\right) .
$$

Bukti. Berdasarkan persamaan (2.5) dan (2.6), turunan bagi (3.4) adalah

$$
\begin{aligned}
D^{\alpha} x(t) & =C_{1} \lambda_{1} E_{\alpha}\left(\lambda_{1} t^{\alpha}\right)+C_{2} \lambda_{2} E_{\alpha}\left(\lambda_{2} t^{\alpha}\right) \\
D^{2 \alpha} x(t) & =C_{1} \lambda_{1}^{2} E_{\alpha}\left(\lambda_{1} t^{\alpha}\right)+C_{2} \lambda_{2}^{2} E_{\alpha}\left(\lambda_{2} t^{\alpha}\right) .
\end{aligned}
$$

Subtitusikan persamaan (3.4), (3.6), dan (3.7) ke dalam ruas kiri persamaan (1.2), diperoleh

$$
C_{1}\left[\lambda_{1}^{2}+a_{0} \lambda_{1}+b_{0}\right] E_{\alpha}\left(\lambda_{1} t^{\alpha}\right)+C_{2}\left[\lambda_{2}^{2}+a_{0} \lambda_{2}+b_{0}\right] E_{\alpha}\left(\lambda_{2} t^{\alpha}\right) .
$$

Karena $\lambda_{1}, \lambda_{2}$ adalah akar dari persamaan (3.3), maka $\lambda_{1}^{2}+a_{0} \lambda_{1}+b_{0}=0$ dan $\lambda_{2}^{2}+a_{0} \lambda_{2}+b_{0}=0$, sehingga (3.8) adalah nol. Ini menunjukkan bahwa (3.4) adalah solusi dari (1.2).

Untuk memperlihatkan bahwa $C_{1}$ dan $C_{2}$ memenuhi sistem persamaan linier (3.5), evaluasi persamaan (3.4) di $t=t_{0}$ dan $t=t_{1}$.

$$
\left(\begin{array}{cc}
E_{\alpha}\left(\lambda_{1} t_{0}^{\alpha}\right) & E_{\alpha}\left(\lambda_{2} t_{0}^{\alpha}\right) \\
E_{\alpha}\left(\lambda_{1} t_{1}^{\alpha}\right) & E_{\alpha}\left(\lambda_{2} t_{1}^{\alpha}\right)
\end{array}\right)\left(\begin{array}{l}
C_{1} \\
C_{2}
\end{array}\right)=\left(\begin{array}{c}
x_{0} \\
x_{1}
\end{array}\right),
$$

yang dalam hal ini $E_{\alpha}\left(\lambda_{1,2} t_{0}^{\alpha}\right)$ dan $E_{\alpha}\left(\lambda_{1,2} t_{1}^{\alpha}\right)$ dapat dihitung dengan menggunakan software Matlab.

Sebagai suatu ilustrasi, perhatikan persamaan diferensial fraksional orde $\left(\frac{2}{6}\right)$ berikut ini:

$$
D^{\frac{2}{6}} x(t)-\frac{1}{4} D^{\frac{1}{6}} x(t)-\frac{1}{8} x(t)=0 \quad t \in\left[\frac{1}{2}, 1\right],
$$

dengan syarat batas

$$
x\left(\frac{1}{2}\right)=1, \quad x(1)=2 .
$$

Solusi bagi persamaan diferensial (3.10) adalah

$$
x(t)=C_{1} E_{\frac{1}{6}}\left(\frac{1}{2} t^{\frac{1}{6}}\right)+C_{2} E_{\frac{1}{6}}\left(-\frac{1}{4} t^{\frac{1}{6}}\right) .
$$

Dengan menggunakan aplikasi Matlab, diperoleh

$$
\left(\begin{array}{l}
C_{1} \\
C_{2}
\end{array}\right)=\left(\begin{array}{c}
3,9706 \\
-8,0153
\end{array}\right)
$$


Jadi, solusi bagi persamaan (3.10) adalah

$$
x(t)=3,9706 E_{\frac{1}{6}}\left(\frac{1}{2} t^{\frac{1}{6}}\right)-8,0153 E_{\frac{1}{6}}\left(-\frac{1}{4} t^{\frac{1}{6}}\right) .
$$

Untuk Kasus 2, solusi persamaan (1.2) dengan syarat batas (1.3) diberikan dalam teorema berikut.

Teorema 3.2. Untuk persamaan diferensial fraksional (1.2), jika $\lambda_{1}, \lambda_{2} \in \mathbb{R}$ dengan $\lambda_{1}=\lambda_{2}$ adalah akar-akar persamaan karakteristik (3.3), maka solusi bagi persamaan (1.2) adalah

$$
x(t)=C_{1} E_{\alpha}\left(\lambda_{1} t^{\alpha}\right)+C_{2} t^{\alpha} E_{\alpha}^{(1)}\left(\lambda_{1} t^{\alpha}\right),
$$

dengan $C_{1}$ dan $C_{2}$ memenuhi sistem persamaan linier berikut.

$$
\left(\begin{array}{ll}
E_{\alpha}\left(\lambda_{1} t_{0}^{\alpha}\right) & t_{0}^{\alpha} E_{\alpha}^{(1)}\left(\lambda_{1} t_{0}^{\alpha}\right) \\
E_{\alpha}\left(\lambda_{1} t_{1}^{\alpha}\right) & t_{1}^{\alpha} E_{\alpha}^{(1)}\left(\lambda_{1} t_{1}^{\alpha}\right)
\end{array}\right)\left(\begin{array}{l}
C_{1} \\
C_{2}
\end{array}\right)=\left(\begin{array}{l}
x_{0} \\
x_{1}
\end{array}\right) .
$$

Bukti. Dari formula (2.2) pada Definisi 2.3 dan berdasarkan turunan fraksional Caputo (2.5) dan (2.6), diperoleh

$$
\begin{aligned}
E_{\alpha}^{(1)}\left(\lambda_{1} t^{\alpha}\right) & =\frac{1}{\Gamma(\alpha+1)}+\frac{2 \lambda_{1} t^{\alpha}}{\Gamma(2 \alpha+1)}+\frac{3 \lambda_{1}^{2} t^{2 \alpha}}{\Gamma(3 \alpha+1)}+\cdots \\
t^{\alpha} E_{\alpha}^{(1)}\left(\lambda_{1} t^{\alpha}\right) & =\frac{t^{\alpha}}{\Gamma(\alpha+1)}+\frac{2 \lambda_{1} t^{2 \alpha}}{\Gamma(2 \alpha+1)}+\frac{3 \lambda_{1}^{2} t^{3 \alpha}}{\Gamma(3 \alpha+1)}+\cdots \\
D^{\alpha}\left(t^{\alpha} E_{\alpha}^{(1)}\left(\lambda_{1} t^{\alpha}\right)\right) & =1+\frac{2 \lambda_{1} t^{\alpha}}{\Gamma(\alpha+1)}+\frac{3 \lambda_{1}^{2} t^{2 \alpha}}{\Gamma(2 \alpha+1)}+\cdots \\
D^{2 \alpha}\left(t^{\alpha} E_{\alpha}^{(1)}\left(\lambda_{1} t^{\alpha}\right)\right) & =2 \lambda_{1}+\frac{3 \lambda_{1}^{2} t^{\alpha}}{\Gamma(\alpha+1)}+\frac{4 \lambda_{1}^{3} t^{2 \alpha}}{\Gamma(2 \alpha+1)}+\cdots
\end{aligned}
$$

Subtitusikan (3.14), (3.17) dan (3.18) ke dalam ruas kiri persamaan (1.2), diperoleh

$$
\begin{aligned}
& C_{1}\left(\lambda_{1}^{2}+a_{0} \lambda_{1}+b_{0}\right) E_{\alpha}\left(\lambda_{1} t^{\alpha}\right)+C_{2}\left(2 \lambda_{1}+a_{0}\right) \\
& +C_{2}\left(3 \lambda_{1}^{2}+2 a_{0} \lambda_{1}+b_{0}\right) \frac{t^{\alpha}}{\Gamma(\alpha+1)}+C_{2}\left(4 \lambda_{1}^{3}+3 a_{0} \lambda_{1}^{2}+2 \lambda_{1} b_{0}\right) \frac{t^{2 \alpha}}{\Gamma(2 \alpha+1)} \\
& +C_{2}\left(5 \lambda_{1}^{4}+4 a_{0} \lambda_{1}^{3}+3 \lambda_{1}^{2} b_{0}\right) \frac{t^{3 \alpha}}{\Gamma(3 \alpha+1)}+\cdots
\end{aligned}
$$

Karena $\lambda_{1}$ adalah akar kembar dari persamaan karakteristik (3.3), maka

$$
\begin{aligned}
\lambda_{1}^{2}+a_{0} \lambda_{1}+b_{0} & =0 \\
2 \lambda_{1}+a_{0} & =0 \\
3 \lambda_{1}^{2}+2 a_{0} \lambda_{1}+b_{0} & =0 \\
4 \lambda_{1}^{3}+3 a_{0} \lambda_{1}^{2}+2 \lambda_{1} b_{0} & =0 \\
5 \lambda_{1}^{4}+4 a_{0} \lambda_{1}^{3}+3 \lambda_{1}^{2} b_{0} & =0
\end{aligned}
$$


dan akibatnya (3.19) adalah nol. Ini menunjukkan bahwa (3.14) adalah solusi dari (1.2). Untuk memperlihatkan bahwa $C_{1}$ dan $C_{2}$ memenuhi sistem persamaan linier (3.15), evaluasi persamaan (3.14) di $t=t_{0}$ dan $t=t_{1}$.

$$
\left(\begin{array}{c}
E_{\alpha}\left(\lambda_{1} t_{0}^{\alpha}\right) t_{0}^{\alpha} E_{\alpha}^{(1)}\left(\lambda_{1} t_{0}^{\alpha}\right) \\
E_{\alpha}\left(\lambda_{1} t_{1}^{\alpha}\right) t_{1}^{\alpha} E_{\alpha}^{(1)}\left(\lambda_{1} t_{1}^{\alpha}\right)
\end{array}\right)\left(\begin{array}{l}
C_{1} \\
C_{2}
\end{array}\right)=\left(\begin{array}{l}
x_{0} \\
x_{1}
\end{array}\right)
$$

yang dalam hal ini $E_{\alpha}\left(\lambda_{1} t_{0}^{\alpha}\right)$ dan $E_{\alpha}\left(\lambda_{1} t_{1}^{\alpha}\right)$ dapat dihitung dengan menggunakan aplikasi software Matlab.

Sebagai suatu ilustrasi, perhatikan persamaan diferensial fraksional orde $\left(\frac{2}{3}\right)$ berikut ini:

$$
D^{\frac{2}{3}} x(t)-\frac{4}{3} D^{\frac{1}{3}} x(t)+\frac{4}{9} x(t)=0 \quad t \in\left[\frac{1}{4}, \frac{3}{4}\right]
$$

dengan syarat batas

$$
x\left(\frac{1}{4}\right)=\frac{1}{5}, \quad x\left(\frac{3}{4}\right)=\frac{2}{3} .
$$

Solusi bagi persamaan (3.21) adalah

$$
x(t)=C_{1} E_{\frac{1}{3}}\left(\frac{2}{3} t^{\frac{1}{3}}\right)+C_{2} t^{\frac{1}{3}} E_{\frac{1}{3}}^{(1)}\left(\frac{2}{3} t^{\frac{1}{3}}\right) .
$$

Dengan menggunakan aplikasi Matlab, diperoleh

$$
\left(\begin{array}{l}
C_{1} \\
C_{2}
\end{array}\right)=\left(\begin{array}{c}
0,2 \\
0,6667
\end{array}\right) \text {. }
$$

Jadi, solusi bagi persamaan (3.21) adalah

$$
x(t)=0,2 E_{\frac{1}{3}}\left(\frac{2}{3} t^{\frac{1}{3}}\right)+0,6667 t^{\frac{1}{3}} E_{\frac{1}{3}}^{(1)}\left(\frac{2}{3} t^{\frac{1}{3}}\right) .
$$

Untuk Kasus 3, solusi persamaan (1.2) dengan syarat batas (1.3) diberikan dalam teorema berikut.

Teorema 3.3. Untuk persamaan diferensial fraksional (1.2), jika $p, q \in \mathbb{R}$ dan $i=$ $\sqrt{-1}$ dengan $\lambda_{1}=p+i q$ dan $\lambda_{2}=p-i q$ adalah akar-akar persamaan karakteristik (3.3), maka solusi umum dari persamaan (1.2) adalah

$$
x(t)=C_{1} E_{\alpha}\left((p+i q) t^{\alpha}\right)+C_{2} E_{\alpha}\left((p-i q) t^{\alpha}\right),
$$

dengan $C_{1}$ dan $C_{2}$ memenuhi sistem persamaan linier berikut.

$$
\left(\begin{array}{ll}
E_{\alpha}\left((p+i q) t_{0}^{\alpha}\right) & E_{\alpha}\left((p-i q) t_{0}^{\alpha}\right) \\
E_{\alpha}\left((p+i q) t_{1}^{\alpha}\right) & E_{\alpha}\left((p-i q) t_{1}^{\alpha}\right)
\end{array}\right)\left(\begin{array}{l}
C_{1} \\
C_{2}
\end{array}\right)=\left(\begin{array}{l}
x_{0} \\
x_{1}
\end{array}\right)
$$

Bukti. Berdasarkan persamaan(2.5) dan (2.6), turunan dari (3.26) adalah

$$
\begin{aligned}
D^{\alpha} x(t) & =C_{1}(p+i q) E_{\alpha}\left((p+i q) t^{\alpha}\right)+C_{2}(p-i q) E_{\alpha}\left((p-i q) t^{\alpha}\right) \\
D^{2 \alpha} x(t) & \left.=C_{1}(p+i q)^{2} E_{\alpha}\left((p+i q) t^{\alpha}\right)+C_{2}(p-i q)^{2} E_{\alpha}\left((p+i q) t^{\alpha}\right)\right) .
\end{aligned}
$$


Subtitusikan, persamaan (3.26), (3.28), dan (3.7) ke dalam ruas kiri persamaan (1.2), diperoleh

$$
\begin{aligned}
& C_{1}\left[(p+i q)^{2}+a_{0}(p+i q)+b_{0}(p+i q)\right] E_{\alpha}\left((p+i q) t^{\alpha}\right) \\
& +C_{2}\left[(p-i q)^{2}+a_{0}(p-i q)+b_{0}(p-i q)\right] E_{\alpha}\left((p-i q) t^{\alpha}\right) .
\end{aligned}
$$

Karena $\lambda_{1}=(p+i q), \lambda_{2}=(p-i q)$ adalah akar dari persamaan (3.3), maka $(p+i q)^{2}+a_{0}(p+i q)+b_{0}(p+i q)=0$ dan $(p-i q)^{2}+a_{0}(p-i q)+b_{0}(p-i q)=0$, sehingga (3.30) adalah nol. Ini menunjukkan bahwa (3.26) adalah solusi bagi persamaan (1.2).

Untuk memperlihatkan $C_{1}$ dan $C_{2}$ memenuhi sistem persamaan linier (3.27), evaluasi persamaan (3.26) di $t=t_{0}$ dan $t=t_{1}$.

$$
\left(\begin{array}{cc}
E_{\alpha}\left((p+i q) t_{0}^{\alpha}\right) & E_{\alpha}\left((p-i q) t_{0}^{\alpha}\right) \\
E_{\alpha}\left((p+i q) t_{1}^{\alpha}\right) & E_{\alpha}\left((p-i q) t_{1}^{\alpha}\right)
\end{array}\right)\left(\begin{array}{l}
C_{1} \\
C_{2}
\end{array}\right)=\left(\begin{array}{l}
x_{0} \\
x_{1}
\end{array}\right)
$$

yang dalam hal ini $E_{\alpha}\left((p \pm i q) t_{0}^{\alpha}\right)$ dan $E_{\alpha}\left((p \pm i q) t_{1}^{\alpha}\right)$ dapat dihitung dengan menggunakan aplikasi software Matlab.

Sebagai suatu ilustrasi, perhatikan persamaan diferensial fraksional orde $\left(\frac{2}{2}\right)$.

$$
D x(t)-\frac{4}{13} D^{\frac{1}{2}} x(t)+\frac{1}{13} x(t)=0 \quad t \in\left[1, \frac{3}{2}\right]
$$

dengan syarat batas

$$
x(1)=2, \quad x\left(\frac{3}{2}\right)=0 .
$$

Solusi bagi persamaan diferensial (3.32) adalah

$$
x(t)=C_{1} E_{\frac{1}{2}}\left(\left(\frac{1}{2+3 i}\right) t^{\frac{1}{2}}\right)+C_{2} E_{\frac{1}{2}}\left(\left(\frac{1}{2-3 i}\right) t^{\frac{1}{2}}\right) .
$$

Dengan menggunakan aplikasi Matlab, diperoleh

$$
\left(\begin{array}{l}
C_{1} \\
C_{2}
\end{array}\right)=\left(\begin{array}{l}
1.2639-1.2763 i \\
1.2639+1.2763 i
\end{array}\right)
$$

Jadi, solusi bagi persamaan (3.32) adalah

$$
x(t)=(1.2639-1.2763 i) E_{\frac{1}{2}}\left(\left(\frac{1}{2+3 i}\right) t^{\frac{1}{2}}\right)+(1.2639+1.2763 i) E_{\frac{1}{2}}\left(\left(\frac{1}{2-3 i}\right) t^{\frac{1}{2}}\right) .
$$

\section{Kesimpulan}

Ada tiga kategori penyelesaian masalah nilai batas untuk persamaan diferensial fraksional linier $2 \alpha$ berikut:

$$
D^{2 \alpha} x(t)+a_{0} D^{\alpha} x(t)+b_{0} x(t)=0, \quad t \in\left[t_{0}, t_{1}\right], \quad m-1<\alpha<m
$$

dengan syarat batas

$$
x\left(t_{0}\right)=x_{0} \quad x\left(t_{1}\right)=x_{1},
$$

yang dalam hal ini $D^{\alpha}$ adalah turunan Caputo. 
1. Jika $\lambda_{1} \neq \lambda_{2}$, dengan $\lambda_{1}, \lambda_{2} \in \mathbb{R}$, maka solusinya adalah

$$
x(t)=C_{1} E_{\alpha}\left(\lambda_{1} t^{\alpha}\right)+C_{2} E_{\alpha}\left(\lambda_{2} t^{\alpha}\right),
$$

dimana $C_{1}$ dan $C_{2}$ memenuhi sistem persamaan linier

$$
\left(\begin{array}{cc}
E_{\alpha}\left(\lambda_{1} t_{0}^{\alpha}\right. & E_{\alpha}\left(\lambda_{2} t_{0}^{\alpha}\right) \\
E_{\alpha}\left(\lambda_{1} t_{1}^{\alpha}\right) & E_{\alpha}\left(\lambda_{2} t_{1}^{\alpha}\right)
\end{array}\right)\left(\begin{array}{l}
C_{1} \\
C_{2}
\end{array}\right)=\left(\begin{array}{c}
x_{0} \\
x_{1}
\end{array}\right) .
$$

2. Jika $\lambda_{1}=\lambda_{2}$ dengan $\lambda_{1}, \lambda_{2} \in \mathbb{R}$, maka solusinya adalah

$$
x(t)=C_{1} E_{\alpha}\left(\lambda_{1} t^{\alpha}\right)+C_{2} t^{\alpha} E_{\alpha}^{(1)}\left(\lambda_{2} t^{\alpha}\right),
$$

dimana $C_{1}$ dan $C_{2}$ memenuhi sistem persamaan linier

$$
\left(\begin{array}{c}
E_{\alpha}\left(\lambda_{1} t_{0}^{\alpha} t_{0}^{\alpha} E_{\alpha}^{(1)}\left(\lambda_{1} t_{0}^{\alpha}\right)\right. \\
E_{\alpha}\left(\lambda_{2} t_{1}^{\alpha} t_{1}^{\alpha} E_{\alpha}^{(1)}\left(\lambda_{2} t_{1}^{\alpha}\right)\right.
\end{array}\right)\left(\begin{array}{l}
C_{1} \\
C_{2}
\end{array}\right)=\left(\begin{array}{c}
x_{0} \\
x_{1}
\end{array}\right) .
$$

3. Jika $\lambda_{1}=p+i q$ dan $\lambda_{2}=p-i q$ dengan $p, q \in \mathbb{R}$ dan $i=\sqrt{-1}$, maka solusinya adalah

$$
x(t)=C_{1} E_{\alpha}\left((p+i q) t^{\alpha}\right)+C_{2} E_{\alpha}\left((p-i q) t^{\alpha}\right),
$$

dimana $C_{1}$ dan $C_{2}$ memenuhi sistem persamaan linier

$$
\left(\begin{array}{ll}
E_{\alpha}\left((p+i q) t_{0}^{\alpha}\right) & E_{\alpha}\left((p-i q) t_{0}^{\alpha}\right) \\
E_{\alpha}\left((p+i q) t_{1}^{\alpha}\right) & E_{\alpha}\left((p-i q) t_{1}^{\alpha}\right)
\end{array}\right)\left(\begin{array}{l}
C_{1} \\
C_{2}
\end{array}\right)=\left(\begin{array}{l}
x_{0} \\
x_{1}
\end{array}\right) .
$$

\section{Ucapan Terima kasih}

Penulis mengucapkan terima kasih kepada Bapak Prof. Dr. Muhafzan, Ibu Dr. Arrival Rince Putri, Bapak Dr. Dodi Devianto, dan Ibu Dr. Lyra Yulianti yang telah memberikan masukan dan saran dalam penyempurnaan penulisan artikel ini.

\section{Daftar Pustaka}

[1] 'Aisy, N.R., Husna, R., 2019, Solusi Sistem Persamaan Diferensial Fractional Linear Orde Fractional Dengan Turunan Tipe Caputo, Jurnal Matematika UNAND, Vol. 8 (2): 101 - 107

[2] Afisha, H.O., 2016, Solusi Persamaan Fraksional Linear Homogen Dengan Metode Mittage-Leffler, Jurnal Matematika Murni dan Terapan"epsilon", Vol $10(1): 21-30$

[3] Bartle, R.G and Donald, R.S., 2010, Introduction to Real Analysis, Fourth Edition. John Wiley and Sons, USA

[4] Ishteva, M.K., 2005, Properties and Application of The Caputo Fractional Operator. Departement of Mathematics Universitat Karlsruhe, Sofia (Bulgaria)

[5] Sari,G.N., Baqi, A.I., 2020, Penggunaaan Metode Mittag-Leffler untuk Menyelesaikan Persamaan Diferensial fractional linier dengan Koefisien Konstan, Jurnal Matematika UNAND, Vol. 9 (2): 107 - 114

[6] Martono,K. 1999. Kalkulus. Erlangga, Jakarta

[7] Miller, K.S and Ross, B., 1993, An Introduction to Fractional Calculus and Fractional Differential Equations. john Wiley and Sons, New York, NY, USA 
Persamaan Diferensial Fraksional Linier Orde $2 \alpha$ dengan Turunan Tipe Caputo 19

[8] Milici, C., Gheorghe, D., and Machado, J.T., 2019, Introduction to Fractional Differential Equations. Springer Nature, Switzerland

[9] Odibat, M.Z., 2009, Analytic Study on Linear Systems of Fractional Differential Equations. Computers and Mathematics with Applications. Elsevier Ltd

[10] Podlubny, I., 1999, Fractional Differential equations. Academic Press, San Diego

[11] Schiff, J.L., 1999, The Laplace Transform . Springer-Verlag, New York. 